\title{
Designing for Different Users and Multiple Devices: A Roadmap towards Inclusive Environments
}

\author{
Ig Ibert Bittencourt ${ }^{1,2}$, Maria Cecília Baranauskas ${ }^{2}$, Diego Dermeval ${ }^{3}$, \\ Juliana Braga ${ }^{4}$, and Roberto Pereira ${ }^{2}$ \\ ${ }^{1}$ Center of Excellence in Social Technologies, Computing Institute, \\ Federal University of Alagoas, Brazil \\ ig.iberteic.ufal.br \\ ${ }^{2}$ Computing Institute, University of Campinas, São Paulo, Brazil \\ \{cecilia, rpereira\}@ic.unicamp.br \\ ${ }^{3}$ Federal University of Campina Grande, Paraíba, Brazil \\ diegodermeval@dsc.ufcg.edu.br \\ ${ }^{4}$ Federal University of ABC, São Paulo, Brazil \\ juliana.braga@ufabc.edu.br
}

\begin{abstract}
The Web can be understood as an ecosystem of interconnected technological resources organized by rules, strategies, organizational structures, and mainly people. Such ecosystem is improving the potential to access knowledge everywhere and at any time. However, for different reasons, this technological extension is not reaching everybody yet. Those without access to knowledge are mainly people with disabilities or living in underserved communities. Nevertheless, the extension of Web technologies to different types of devices (such as mobile phones, tablets, TV) and their connections have the potential to increase the solutions to reach people with different needs through different devices. For this reason, several research and industrial studies have been proposed to design interfaces for multiple devices considering differences among users. In this paper, we present results of a systematic review on literature to build a roadmap towards inclusive environments. Additionally, the study also suggests existing tools to support the design of accessible applications for multiple devices. A significant result of this review is the lack of studies addressing underserved communities.
\end{abstract}

Keywords: Inclusive Environments, Portability, User Interface Design, Inclusiveness, Diversity, Multiple Devices.

\section{Introduction}

Several organizations around the world have undertaken work programs to establish electronic communication via Web technologies. The Web can be understood as an ecosystem of interconnected technological resources organized by rules, strategies, organizational structures, and mainly people. As a result, this ecosystem is improving the potential of access to knowledge everywhere and at any time, and is becoming a way to tackle the challenge of providing a participative and universal access to 
knowledge. Universal access has been considered one of the great challenges of several International Communities around the world [1] [2]. This challenge is about the use of technologies to ensure access to knowledge in a participative and personalized way for the citizen, taking into account the diversity of people and, consequently, different ${ }^{1}$ users' needs encompassing disability issues as well as social problems (e.g.,

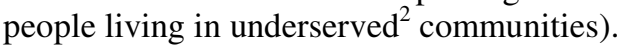

The accessibility challenge regards ensuring access to information and functionalities to all potential users of technology. As a matter of fact, a valuable body of research and best practices has been developed to address Web accessibility. However, the challenges of Web accessibility have increased substantially due both to the extension of Web technologies to different kind of devices (e.g., mobile phones, tablets, TV) and to their possibility of interactions. On one hand, the Web movement beyond desktop to different devices increased the challenges of accessibility. On the other hand, this movement amplified the possibilities to ensure access to information independently of the place or the knowledge domain. For this reason, many research and industrial studies have been proposed to design interfaces for multiple devices and different users — such as [2] [3] [4] —; however, no systematic review has been conducted to provide an overview of the design of inclusive environments for different users and multiple devices.

The goal of this paper is to present results of a systematic review about interface design approaches addressing multiple devices and different users, and, at the same time, to identify the tools available to build accessible applications aiming to reach people with different disabilities and/or living in underserved communities.

This paper is organized as follows: Section 2 describes the research method of the study; Section 3 gives an overview of the studies included in the work; Section 4 presents the main results of this systematic review with a discussion on the reported results. Finally, Section 5 summarizes this work, presents our conclusions and points out future works.

\section{The Method}

The research in this work was undertaken as a systematic literature review (SLR) to provide a repeatable and formal process to document relevant papers about portability on inclusive social web. As a result of identifying, interpreting and evaluating their data, it is possible to find evidence on which to base conclusions according to the research questions. The conclusions are commonly used to support or contradict claims made by researchers, identify gaps in existing research, provide motivation for new research, and supply a context for the new research [5].

\footnotetext{
${ }^{1}$ In this paper, we consider the term "different users" or "different conditions" as the users with disabilities (sensorial impairment, motor impairment, and cognitive impairment), social problems (underserved or illiterate people) and ageing (elderly).

2 In this paper, we consider the term underserved as the people or communities living in areas without good access to technology and/or internet, such as rural areas and low income areas in the periphery of large cities.
} 
According to [5], a systematic review is composed by three phases (planning, conducting, and reporting) divided into several steps, which are: 1) Planning the Review (Identification of the need for a systematic review; Development of a review protocol); 2) Conducting the Review (Identification of research; Selection of the studies; Study Quality assessment; Data extraction and monitoring; Data analysis; Data synthesis); 3) Reporting the review (Report-writing).

\subsection{Review Questions}

The goals of this systematic review were: i) to summarize the research in this topic; and ii) to present a roadmap towards inclusive environments. As the goal of this systematic review was to gather knowledge about the design of inclusive environments for different users and multiple devices, the high-level question of this study was:

\section{How researchers are designing applications for different users and multiple devices?}

Based on this research question, other two more specific questions were raised. The questions and their motivations are described in Table 1.

Table 1. Research Questions and Motivations

\begin{tabular}{|c|c|}
\hline Research Question & Motivation \\
\hline $\begin{array}{l}\text { RQ1. Which interface design approaches are } \\
\text { being used to address multiple devices and } \\
\text { users with different conditions? }\end{array}$ & $\begin{array}{l}\text { This question provides a starting point to } \\
\text { understand how designers conduct the inter- } \\
\text { face specification for multiple devices. The } \\
\text { answer to this question is important to under- } \\
\text { stand how people with different conditions are } \\
\text { being considered in the interface design } \\
\text { process. }\end{array}$ \\
\hline $\begin{array}{l}\text { RQ2. Which tools are being used to support } \\
\text { the design of inclusive applications for mul- } \\
\text { tiple devices? }\end{array}$ & $\begin{array}{l}\text { This question presents the different solutions } \\
\text { (i.e., software, frameworks, authoring tools, } \\
\text { architectures, and so on) to build portable } \\
\text { applications for all. The answer to this question } \\
\text { is important to identify the different solutions } \\
\text { regarding the adopted software engineering } \\
\text { practice. }\end{array}$ \\
\hline
\end{tabular}

\subsection{Sources and Search Selection Criteria}

The first step to perform our review was to define the search selection criteria. Due to the fact that this review has several sources to consider, two kinds of search strategies were considered (based on [6]), which were automatic and manual search. Automatic search was done according to the specification of the search terms (i.e., search string). Although automatic search covers a large range of relevant papers, it is also important 
to search in specific and specialized sources to improve the coverage. For this reason, a manual search in some of the most important conferences and journals of the $\mathrm{Hu}-$ man-Computer Interaction area was taken into account.

Hereafter, the search terms definition and the digital libraries (DLs) selection regarding the automatic search are explained. According to the research questions aforementioned, a set of relevant terms was defined, such as: cross-device, disabilities, underserved communities, design interfaces, approaches, multiple devices, different users, tools, and inclusive. After that, these terms were categorized and their related terms were identified. The terms were identified based on: i) expertise of the authors; ii) analysis of terms present in a HCI systematic review available at [7]; iii) TagCloud for HCI presented in Fig. 1 and iv) suggested topics for contributions to the Interact 2013 Conference.

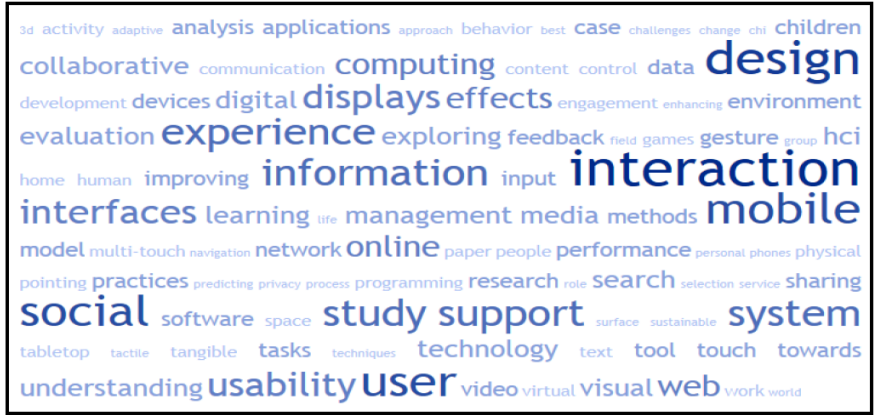

Fig. 1. TagCloud for HCI [8]

The related terms for the main words are described as follows:

- Tool = environment, framework, authoring, architecture, software, ambient, "reference model";

- Disabilities = Inclusive, inclusiveness, inclusivity, accessibility, disability, assistive, underserved, "marginalized communities", "design for all", "universal access", elderly, "older adults", diversity;

- Multiple Device = "cross-device", multimodal, migration, "different devices", "device-independent", "migratory interfaces", "distributed interfaces", "plastic user interfaces", "flexible user interfaces", "flexible interfaces", "distributed user interfaces", portability, "portable web applications", "portable systems", interoperability;

- Interaction design = "adaptable interface", "adaptable user interfaces", "interaction resources", "responsive web design", "universal design”, "inclusive design”, "process model”, "adaptable model”, "system design”, "meta-design”.

By contrast, the set of digital libraries was defined according to the most popular and traditional DLs. However, the SpringerLink digital library was excluded due to search restrictions and its intersection with others DLs. The selected DLs were:

- ISI Web of Science (http://www.isiknowledge.com);

- Scopus (www.scopus.com/scopus/home.url); 
- $\quad$ ACM Digital Library (http://portal.acm.org);

- IEEE Xplore (http://www.ieee.org/web/publications/xplore/);

- ScienceDirect (http://www.sciencedirect.com).

After the definition of relevant terms and DLs, the search string for automatic search on the mentioned digital libraries was built as follows:

((tool OR environment OR framework OR authoring OR architecture OR software OR ambient OR "reference model")

AND

(inclusive OR inclusiveness OR inclusivity OR "inclusive web" OR "inclusive social web" OR accessibility OR disability OR disabilities OR assistive OR underserved OR "marginalized communities" OR "design for all" OR "universal access" OR "universal design" OR "designing for diversity" OR "design for diversity" OR "design diversity" OR diversity)

AND

("Multiple Device" OR "Cross-device" OR "Multimodal" OR migration OR "different devices" OR "device-independent" OR "migratory interfaces" OR "distributed interfaces" OR "plastic user interfaces" OR "flexible user interfaces" OR "flexible interfaces" OR "distributed user interfaces" OR portability OR "portable web applications" OR "portable systems" OR "information interoperability" OR "knowledge interoperability")

AND

("Interaction design" OR "adaptable interface" OR "adaptable user interfaces" OR "interaction resources" OR "responsive web design" OR "universal design" OR "inclusive design" OR "process model" OR "adaptable model" OR "meta-design" OR "meta design" OR metadesign OR "participative design" ) )

Moreover, in order to perform the manual search, two relevant conferences and journals in the Human-Computer Interaction area were considered (see Table 2). It is important to note that other Journals and Conferences could have been considered for manual search, but the Journals were chosen based on their Impact Factor. In addition, we could not have access to the library of some journals, such as the International Journal of Human-Computer Interaction. With regards to conferences, we initially added the ACM SIGCHI Conference on Human Factor in Computing Systems, but the list of published articles in this conference would represent half of the whole search space, unbalancing the study.

Table 2. Relevant journals and conferences on the Human-Computer Interaction area

\begin{tabular}{l}
\hline Journals \\
\hline 1. International Journal of Human Computer Studies \\
2. Interacting with Computers \\
\hline Conferences \\
\hline 1. IFIP INTERACT \\
2. Cross-Disciplinary Conference on Web Accessibility \\
\hline
\end{tabular}




\subsection{Inclusion and Exclusion Criteria}

The aim of defining a criterion is to really identify those primary studies that provide direct evidence about the research questions and also to reduce the likelihood of bias [5]. Regarding the inclusion criteria, articles written in the last ten years related to any of the research questions were considered. The exclusion criteria involve papers not related to the research questions, papers which were not in English, short papers ${ }^{3}$, duplicate studies and papers before $2002^{4}$. The summarized inclusion and exclusion criteria are presented in Table 3.

Table 3. Inclusion and exclusion criteria

\begin{tabular}{l}
\hline Inclusion criteria \\
\hline Peer-reviewed studies that provided answers to the research questions \\
Studies that focus on design approaches for multiple devices \\
Studies that focus on design approaches for different users' needs \\
Studies that focus on assistive technologies for different users' needs \\
Studies published since 2002 \\
\hline Exclusion criteria \\
\hline Short-papers \\
Non peer-reviewed studies \\
Studies that are not related to research questions \\
Duplicated studies \\
Studies before 2002 \\
Non English papers
\end{tabular}

\subsection{Data Extraction}

After the definition of the search and the selection processes, a data extraction process was performed by reading the abstract and screening the full-text of each one of the selected papers. In order to guide this data extraction, the data collection from Biolchini et al. [9] was adapted as follows:

- Paper Information: Study Reference (ID); Source; Year; Source Type (Journal or Conference); Affiliations; Authors list; Paper Title; Google Scholar Citation;

- Context: (Industry and Academia);

- Device Types: (Desktop, Web, Tablet, TV, Mobile Phones, PDA, Tabletop, Braille Notes);

- Target Audience: (Blind/Visual Impairment; Deaf/Hearing Impairment; Motor/ Mental; Underserved people; Elder);

\footnotetext{
${ }^{3}$ Short-papers were excluded because they usually represent ongoing research.

${ }^{4}$ Due to the rapid evolvement of web technologies and hardware devices, the older inclusive solutions for multiple devices lack the benefits and potential of current devices. For this reason, we decided to limit our review to the last decade.
} 
- Design Interface Approach: (User-Centered; Task-Centered; Participatory; Scenario-Based; Ethnographic Methods; Design per Target; Model-based; Automatically Generated; Multi-tier; Universal Design; User Sensitive Inclusive Design);

- Use or propose any tool? (Yes; No);

- Tool Type: (API; Design Pattern; Framework; Platform; Software Product Line; Authoring; MDA; Reference Model; Middleware; Architecture);

- Study Type: (Controlled experiments; Quasi-experiments; Case Study; Survey; Ethnography; Action Research);

- Subjective results extraction.

\section{Overview of the Included Studies}

This section presents the included studies according to the automatic and manual search (see Fig. 2). Firstly, the automatic search was conducted at each digital library. Then, an iterative process was applied to exclude the not relevant papers based on the exclusion criteria. The exclusion criteria were applied according to the analysis of the abstract, full-text screening and finally the duplicate papers. In a similar way, the process was applied to the manual search.

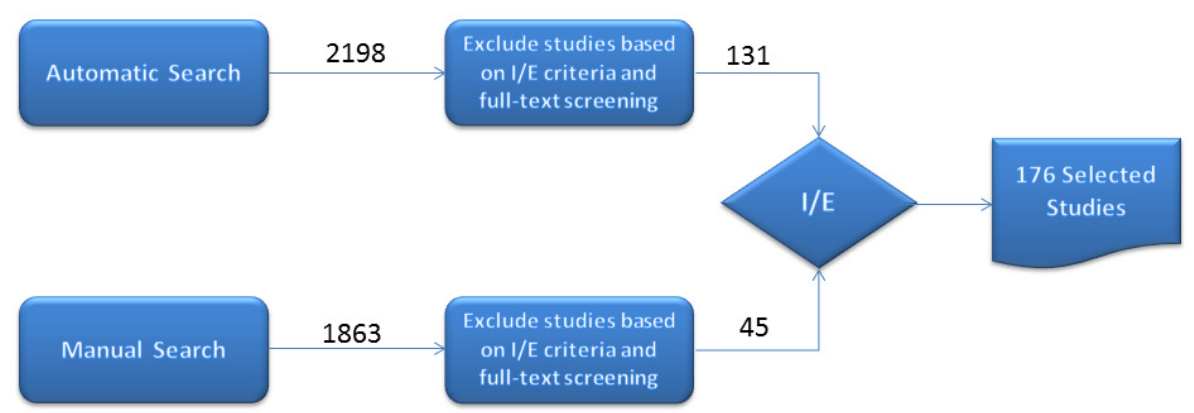

Fig. 2. Search process and selected studies

The automatic and manual query was conducted in the period between December $4^{\text {th }}$ (2012) and January $11^{\text {th }}(2013)$ and the data was extracted by two people. The results per each digital library, conference and journal are shown in Fig. 3.

Fig. 3 (Manual search) presents that the IFIP Interact (31\%; 14 studies) and the W4A - Cross-disciplinary Conference on Web Accessibility (27\%; 12 studies) - were the largest vehicles of relevant studies about portability on inclusive web. However, other vehicles were identified as relevant when the automatic search was applied, such as the ACM SIGCHI Conference on Human Factors in Computing Systems (6.25\%; 8 studies), the ACM SIGACCESS conference on Computers and accessibility (4.69\%, 6 studies) - and the ICCHP -International Conference on Computers Helping People With Special Needs (4.69\%; 6 studies). 

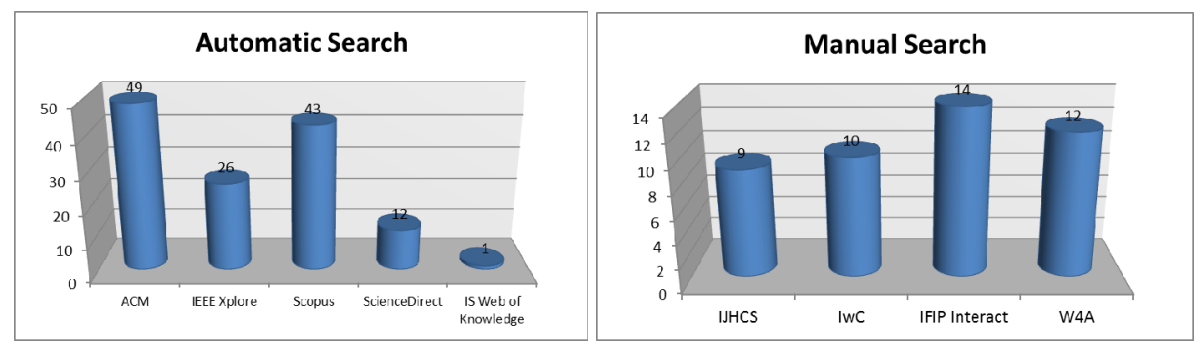

Fig. 3. Automatic and Manual results

From a temporal point of view, it is noticed in the trend curve an increasing number of publications in the context of this review since 2003 (see Fig. 4). It is important to note that there are no works from the year 2002. The first study was published only in 2003. By contrast, there is a decrease in the number of publications in some years (2008, 2009, and 2012).

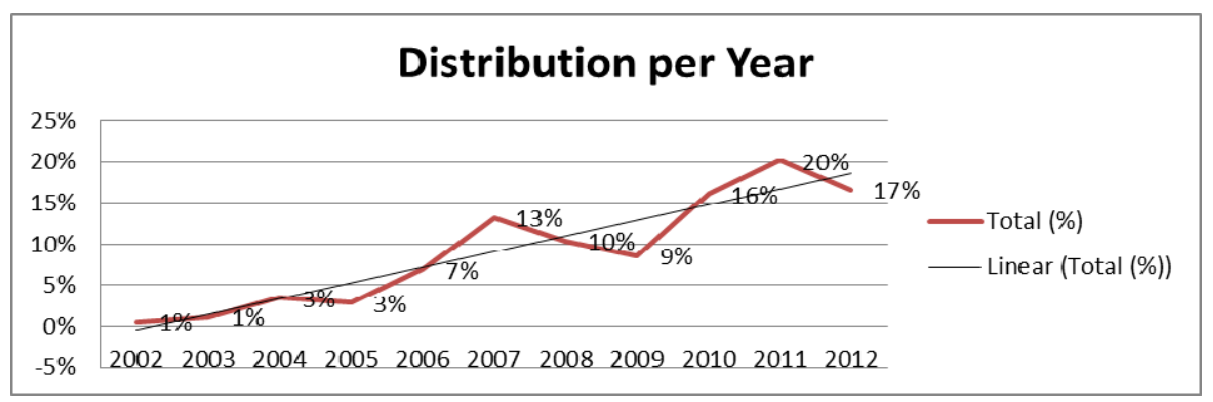

Fig. 4. Distribution of publications per year

Since this review began on December 2012, a possible cause of this decreasing in 2012 is that some papers were still under publication process, thus it is natural that some papers were not available online yet. Therefore, we can see, in general, an increase in the number of publications (based on their linear progression). The significant increase of publications on portability in inclusive web reflects the need for convergence of technologies and, at the same time, the importance of deploying inclusive solutions.

The study holds contributions from 35 countries located in all the continents. Although all the continents are represented in the included papers, there is a concentration in the Americas (26.34\%) and Europe (62.44\%). Table 4 presents the publications per authors country. Furthermore, according to the distribution of the included papers, most of the related papers were published in conferences $(66 \%)$ instead of journals $(34 \%)$, considering both the automatic and manual search. 
Table 4. Publications per country

\begin{tabular}{|c|c|c|}
\hline Country & Works & Total (\%) \\
\hline United States of America & 29 & $14.15 \%$ \\
\hline United Kingdom & 27 & $13.17 \%$ \\
\hline Brazil & 16 & $7.80 \%$ \\
\hline Spain & 15 & $7.32 \%$ \\
\hline Portugal & 11 & $5.37 \%$ \\
\hline Belgium & 10 & $4.88 \%$ \\
\hline Italy & 10 & $4.88 \%$ \\
\hline France & 9 & $4.39 \%$ \\
\hline Germany & 9 & $4.39 \%$ \\
\hline Greece & 7 & $3.41 \%$ \\
\hline Japan & 7 & $3.41 \%$ \\
\hline Austria & 6 & $2.93 \%$ \\
\hline Finland & 6 & $2.93 \%$ \\
\hline Canada & 5 & $2.44 \%$ \\
\hline Australia & 4 & $1.95 \%$ \\
\hline Sweden & 4 & $1.95 \%$ \\
\hline South Korea & 3 & $1.46 \%$ \\
\hline Norway & 3 & $1.46 \%$ \\
\hline South Africa & 3 & $1.46 \%$ \\
\hline Others & 21 & $10.34 \%$ \\
\hline
\end{tabular}

\section{$4 \quad$ Results}

As described in Section 2, three research questions drove this systematic review. Based on the research questions, the string search was built and the type of data extraction defined. According to the data extraction, the addressed conditions of most users were Blind or Visual Impairment (24\%; 58 studies), Mental (14\%; 34 studies) and Motor (14\%; 34 studies). One of the important points about this information is that although the number of deaf people or with hearing impairment is relatively high in the general population, the number of studies addressing this disability in the review was very low (see Fig. 5).

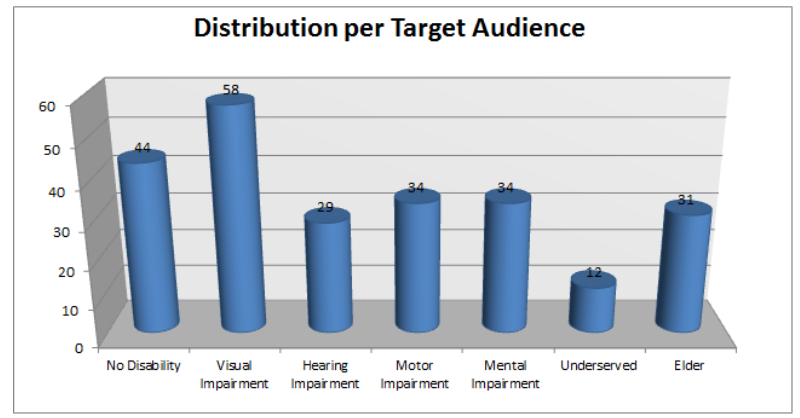

Fig. 5. Distribution of publications per target audience 
The following subsections present and discuss the results for the research questions. Moreover, a specific subsection discusses the works that address underserved communities, due to the reduced amount of papers identified for this audience in the study. In the end of this section, threats to the validity of this review are also discussed.

\subsection{Inclusive Applications for Multiple Devices}

Table 5 presents the distribution of papers according to device type. Most of the solutions were proposed for mobile phones (29.84\%; 94 studies) and Web (18.73\%; 59 studies). It is worth noting that the number of solutions for tablets is still small (8.25\%; 26 studies); this may happen especially because tablets have started to become popular more recently than mobile phones. Nevertheless, an increasing in their use is expected since they have the potential to provide access to underserved communities. Although there are 29 studies in other categories of Device Types, 21 studies $(6.67 \%)$ are not related or did not define the device.

Table 5. Distribution per device type

\begin{tabular}{|c|c|c|}
\hline Device type & Works & Total $(\%)$ \\
\hline Mobile Phones & 94 & $29.84 \%$ \\
\hline Web & 59 & $18.73 \%$ \\
\hline Desktop & 49 & $15.56 \%$ \\
\hline PDA & 44 & $13.97 \%$ \\
\hline Tablet & 26 & $8.25 \%$ \\
\hline TV & 14 & $4.44 \%$ \\
\hline Others & 29 & $9.21 \%$ \\
\hline
\end{tabular}

Table 6 presents the distribution per tool type. Frameworks and platforms are in the top of the list, while the Software Product Line (SPL) approach is not mentioned, suggesting a gap between the Human Computer Interaction and the Software

Table 6. Distribution per tool type

\begin{tabular}{|c|c|c|}
\hline Tool type & Works & Total $(\%)$ \\
\hline Framework & 29 & $16.48 \%$ \\
\hline Application & 24 & $13.64 \%$ \\
\hline Reference Model & 21 & $11.93 \%$ \\
\hline Platform & 20 & $11.36 \%$ \\
\hline Architecture & 7 & $3.98 \%$ \\
\hline Authoring & 4 & $2.27 \%$ \\
\hline MDA & 3 & $1.70 \%$ \\
\hline Design Pattern & 2 & $1.14 \%$ \\
\hline API & 2 & $1.14 \%$ \\
\hline Hardware & 2 & $1.14 \%$ \\
\hline Middleware & 1 & $0.57 \%$ \\
\hline
\end{tabular}


Engineering issues. SPL is one of the most sophisticated concepts in the Software Engineering area with regard to software reuse and flexibility, since it allows a strategic reuse that provides a platform which can be easily adapted according to users' specific needs in a specific domain [10].

In addition, it can be noticed that half of the papers that presented tools provide an inclusive solution (50\%). However, only $15 \%$ of the selected papers proposed inclusive tools for multiple devices, as illustrated in Fig. 6. It is important to observe that by inclusive tools we mean support tools to generate inclusive applications. Additionally, most of the inclusive tools for multiple devices are Frameworks $(37 \%)$ and Platforms (32\%).

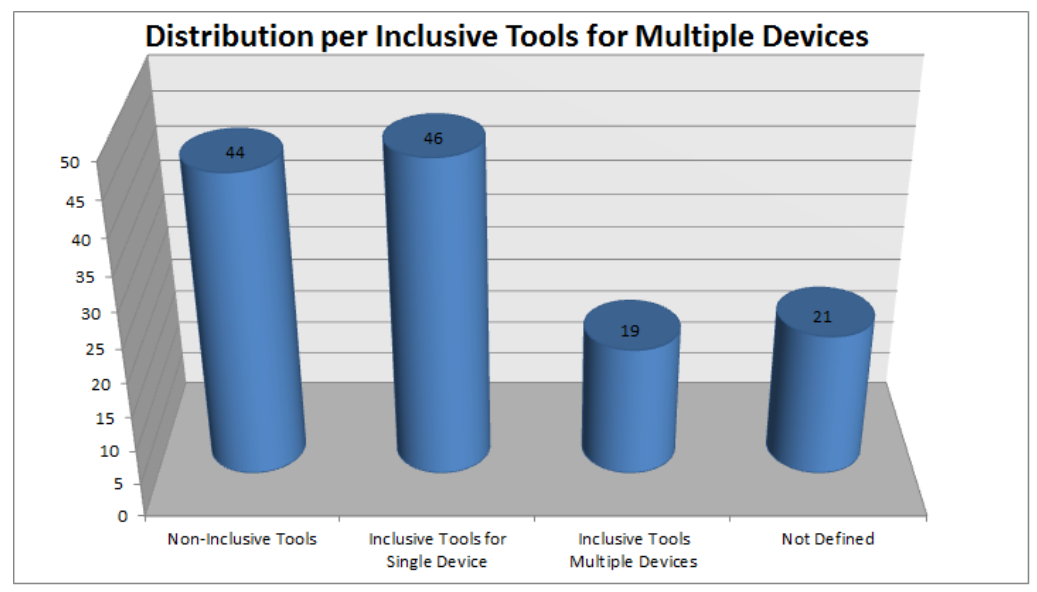

Fig. 6. Graphic about inclusive tools for multiple devices

The list of papers that propose inclusive tools for multiple devices is presented in Table $7^{5}$ (papers which did not define the tool type were not included).

Table 7. List of support tools to generate inclusive tools for multiple devices

\begin{tabular}{|c|c|c|}
\hline Study Ref. & Paper Title & $\begin{array}{l}\text { Technology } \\
\text { Type }\end{array}$ \\
\hline SACM19 & $\begin{array}{l}\text { Distributed Intelligence: Extending the Power of the Unaided, Individu- } \\
\text { al Human Mind }\end{array}$ & Platform \\
\hline SACM20 & $\begin{array}{l}\text { Towards Ubiquitous Accessibility: Capability-based Profiles and Adap- } \\
\text { tations, Delivered via the Semantic Web }\end{array}$ & Platform \\
\hline SACM27 & $\begin{array}{l}\text { MyUI: Generating Accessible User Interfaces from Multimodal Design } \\
\text { Patterns }\end{array}$ & Framework \\
\hline SACM62 & $\begin{array}{l}\text { The Potential of Adaptive Interfaces as an Accessibility Aid for Older } \\
\text { Web Users }\end{array}$ & Platform \\
\hline SACM68 & Accessibility of Dynamic Adaptive Web TV Applications & Framework \\
\hline
\end{tabular}

\footnotetext{
${ }^{5}$ The list of the papers is available at http://www. nees.com.br/interact
} 
Table 7. (Continued)

\begin{tabular}{|c|c|c|}
\hline Study Ref. & Paper Title & $\begin{array}{l}\text { Technology } \\
\text { Type }\end{array}$ \\
\hline SACM70 & $\begin{array}{l}\text { Design, Adoption, and Assessment of a Socio-Technical Environment } \\
\text { Supporting Independence for Persons with Cognitive Disabilities }\end{array}$ & Platform \\
\hline SACM75 & $\begin{array}{l}\text { Agent-Based Architecture for Implementing Multimodal Learning } \\
\text { Environments for Visually Impaired Children }\end{array}$ & Framework \\
\hline SIEEE07 & A-CitizenMobile: A Case Study for Blind Users & Framework \\
\hline SIEEE10 & $\begin{array}{l}\text { An Open Architecture to Develop a Handheld Device for Helping } \\
\text { Visually Impaired People }\end{array}$ & API \\
\hline SIEEE11 & A Framework for Designing Flexible Systems & Framework \\
\hline SIEEE30 & $\begin{array}{l}\text { i*Chameleon: A Unified Web Service Framework for Integrating Mul- } \\
\text { timodal Interaction Devices }\end{array}$ & Framework \\
\hline SSD13 & Automatically generating personalized user interfaces with Supple & Platform \\
\hline SSCOPUS25 & Rapid Prototyping of Adaptable User Interfaces & Platform \\
\hline SSCOPUS 38 & $\begin{array}{l}\text { A Novel Design Approach for: Multi-device Adaptable User Interfaces: } \\
\text { Concepts, Methods and Examples }\end{array}$ & Framework \\
\hline SSCOPUS 40 & $\begin{array}{l}\text { The Contribution of Multimodal Adaptation Techniques to the GUIDE } \\
\text { Interface }\end{array}$ & Platform \\
\hline SSCOPUS 69 & $\begin{array}{l}\text { Contributions of Dichotomic View of plasticity to seamlessly embed } \\
\text { accessibility and adaptivity support in user interfaces }\end{array}$ & Architecture \\
\hline SSCOPUS 80 & $\begin{array}{l}\text { Assistive smartphone for people with special needs : The Personal } \\
\text { Social Assistant }\end{array}$ & Application \\
\hline SSCOPUS 85 & $\begin{array}{l}\text { Attuning speech-enabled interfaces to user and context for inclusive } \\
\text { design: technology, methodology and practice }\end{array}$ & Application \\
\hline
\end{tabular}

Fig. 7 presents the type of empirical study applied to evaluate the tools. More than $50 \%$ of the works applied evaluation by an empirical case study. In addition, only $25 \%$ of the works applied some kind of experiment. By contrast, survey studies were $5 \%$.

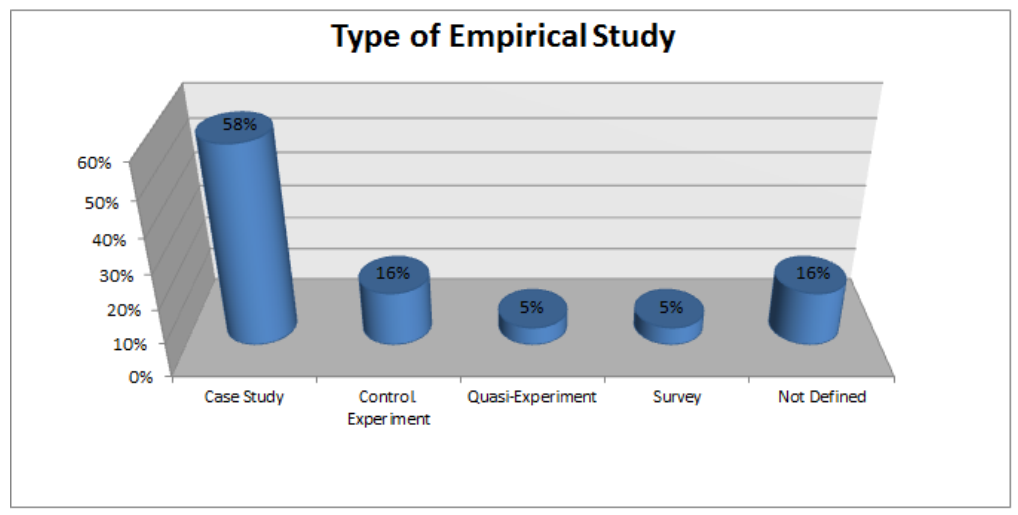

Fig. 7. Type of Empirical Study of the Inclusive Tools for Multiple Devices 
It is also important to identify which of these studies address the design for diversity. For this reason, Table 8 presents them grouped by tools for one target audience and for diversity. As a result, only 4.54\% (6 studies) of the inclusive tools for multiple devices (see Fig. 6) address inclusive tools for different users, while $7.63 \%$ (10 studies) address tools for one target device.

Table 8. List of inclusive studies for multiple devices based on the target audience

\begin{tabular}{ccc}
\hline Technology Type & For one Target Audience & For Diversity \\
\hline Framework & SACM27; SACM75; & SACM68; SIEEE11; SIEEE30; SSco- \\
& SIEEE07 & pus38 \\
Platform & SACM19; SACM20; & \\
Application & SACM62; SACM70; SSD13 & SScopus80; SScopus85 \\
API & - & - \\
Architecture & SIEEE10 & - \\
\hline
\end{tabular}

\subsection{Interface Design Approaches for Diversity}

The distribution of the included studies according to the Interface Design approaches (Table 9) shows that more than 50\% of the studies apply User-centered, participatory or automatically generated approach. However, more than 15 interface design approaches were identified, which turned the data classification, organization, and analysis much sparse.

Table 9. Distribution per Interface Design Approach

\begin{tabular}{lcc}
\hline \multicolumn{1}{c}{ ID Approach } & Works & Total (\%) \\
\hline User-Centered & 31 & $19.62 \%$ \\
Automatically Generated & 27 & $17.09 \%$ \\
Participatory & 25 & $15.82 \%$ \\
Model-Based & 17 & $10.76 \%$ \\
Task-Centered & 15 & $9.49 \%$ \\
User-Sensitive Inclusive Design & 10 & $6.33 \%$ \\
Design Per Target Device & 9 & $5.70 \%$ \\
Ethnographic & 9 & $5.70 \%$ \\
Scenario-Based & 7 & $4.43 \%$ \\
Others & 8 & $5.06 \%$ \\
\hline
\end{tabular}

Moreover, as presented in Table 10, only few studies (13.79\%; 20 studies) present a design approach considering user diversity in the application development.

Conversely, although there are 19 studies addressing Interface Design approaches for diversity, only 3 (three) studies also addressed multiple devices, as depicted in Table 11. Among these studies, two of them apply automatic interface generation and 
Table 10. Distribution per focus on diversity

\begin{tabular}{lccc}
\hline \multicolumn{1}{c}{ ID Approach } & No Disability & For one Target Audience & For Diversity \\
\hline Participatory & $4.83 \%$ & $6.90 \%$ & $4.14 \%$ \\
Automatically Generated & $11.03 \%$ & $4.83 \%$ & $3.45 \%$ \\
User-Centered & $7.59 \%$ & $8.97 \%$ & $3.45 \%$ \\
Model-Based & $9.66 \%$ & $0.00 \%$ & $2.07 \%$ \\
User-Sensitive Inclusive Design & $0.00 \%$ & $4.83 \%$ & $0.69 \%$ \\
Design Per Target Device & $4.14 \%$ & $2.07 \%$ & $0.00 \%$ \\
Task-Centered & $6.21 \%$ & $4.14 \%$ & $0.00 \%$ \\
Scenario-Based & $3.45 \%$ & $2.07 \%$ & $0.00 \%$ \\
Ethnographic & $2.07 \%$ & $3.45 \%$ & $0.00 \%$ \\
\hline
\end{tabular}

the other two use participatory design. Besides, two studies evaluated their tools by some kind of experimental research, while the other two papers performed evaluation by an empirical case study.

Table 11. List of studies from Table 10 for Diversity and Multiple Devices

\begin{tabular}{clccc}
\hline Study Ref. & \multicolumn{1}{c}{ Paper Title } & ID Approach & $\begin{array}{c}\text { Study } \\
\text { Type }\end{array}$ \\
\hline \multirow{2}{*}{ SACM68 } & $\begin{array}{l}\text { Accessibility of Dynamic Adaptive Web TV } \\
\text { Applications }\end{array}$ & $\begin{array}{l}\text { Automatically } \\
\text { Generated }\end{array}$ & Case Study \\
SIEEE11 & $\begin{array}{l}\text { A Framework for Designing Flexible Systems } \\
\text { Pttuning speech-enabled interfaces to user and } \\
\text { SScopus85 }\end{array}$ & $\begin{array}{l}\text { Context for inclusive design: technology, metho- } \\
\text { dology and practice }\end{array}$ & Participatory & $\begin{array}{c}\text { Controlled } \\
\text { Experiment }\end{array}$ \\
\hline
\end{tabular}

\subsection{Solutions for Underserved Communities}

This section discusses the studies with a focus on underserved communities. Indeed, only 12 studies addressed this topic which is also the less discussed target audience identified in this systematic review - representing only 5\% (see Fig. 5). The full list of studies attending underserved communities is presented in Table 12.

It is worth noting that less than half of the underserved people studies involve researchers from countries where the researches were developed. Another important point to highlight is the reduced number of studies about underserved people coming from the HCI community, which means there is a need for cooperative work from different communities with the Human-Computer Interaction community.

As a roadmap regarding studies about underserved communities, most of the studies proposed the use of mobile devices as the best technology. The main reason seems to be that underserved communities have bad access to electricity, internet, and so on. Moreover, we realized that several studies with regards underserved communities refer also to illiterate people. In addition, the most common user interface type 
Table 12. List of studies addressing underserved communities

\begin{tabular}{|c|c|c|}
\hline Study Reference & Paper Title & Countries \\
\hline SACM30 & $\begin{array}{l}\text { Comparing Semiliterate and Illiterate Users' Ability to } \\
\text { Transition from Audio+Text to Text-Only Interaction }\end{array}$ & Canada and India \\
\hline SACM41 & Designing with Mobile Digital Storytelling in Rural Africa & $\begin{array}{l}\text { Australia and } \\
\text { South Africa }\end{array}$ \\
\hline SACM52 & Universal Accessibility As A Multimodal Design Issue & $\begin{array}{l}\text { Spain and Serbia } \\
\text { and Montenegro }\end{array}$ \\
\hline SACM58 & $\begin{array}{c}\text { Cultural Coding and De-Coding as Ways of Participation: } \\
\text { Digital Media for Marginalized Young People }\end{array}$ & USA and Belgium \\
\hline SACM86 & $\begin{array}{l}\text { Technology-Supported Cross-Cultural Collaborative Learn- } \\
\text { ing in the Developing World }\end{array}$ & USA \\
\hline SScopus 35 & $\begin{array}{l}\text { Pushing personhood into place: Situating media in rural } \\
\text { knowledge in Africa }\end{array}$ & $\begin{array}{l}\text { South Africa, } \\
\text { Namibia and } \\
\text { Denmark }\end{array}$ \\
\hline SIWC14 & $\begin{array}{l}\text { Designing new technologies for illiterate populations: A } \\
\text { study in mobile phone interface design }\end{array}$ & United Kingdom \\
\hline SW4A10 & $\begin{array}{c}\text { The Spoken Web Application Framework User } \\
\text { Generated Content and Service Creation through lowend } \\
\text { mobiles }\end{array}$ & India \\
\hline SW4A11 & $\begin{array}{l}\text { Developing Countries; Developing Experiences: Approaches } \\
\text { to Accessibility for the Real World }\end{array}$ & United Kingdom \\
\hline SW4A12 & $\begin{array}{l}\text { Designing for Auditory Web Access: Accessibility and } \\
\text { Cellphone Users }\end{array}$ & USA \\
\hline SW4A13 & $\begin{array}{l}\text { Exploring Web Accessibility Solutions in Developing Re- } \\
\text { gions as Innovations for the Benefit of All }\end{array}$ & France \\
\hline SW4A14 & $\begin{array}{l}\text { Designing new technologies for illiterate populations: A } \\
\text { study in mobile phone interface design }\end{array}$ & United Kingdom \\
\hline
\end{tabular}

was based on Voice or Web. Although Voice approach is commonly used, it does not solve the problem of illiteracy. Another important point is that only 2 studies proposed a software solution, while the others proposed a reference model or a new hardware. Finally, only four studies address the context of developing country.

\subsection{Discussion and other Related Work}

This section focuses on how the systematic review tackled the three research questions and discusses about the important conclusions obtained from the analysis of the papers included in this review. As a result of this review, it was possible to identify the interface design approaches and the tools according to specific user conditions and also to specific devices.

With regards to the RQ1 (Which interface design approaches are being used to address multiple devices and users with different conditions?), only a very limited 
number of papers ( 3 studies, as presented in Table 11) was identified from the whole list of studies (see Fig. 2), representing 1.70\%. One important point is that the Interface design approaches were only the Automatically Generated Interface (from 2012) and the Participatory Design (from 2008 and 2011). This means that the studies were focused on ID approaches to tackle the first phases of software development lifecycle (before software implementation), while other part of the studies were focused on implementation, test, and deployment phases. Only one study raised (SIEEE11) the importance of user involvement during software evolution.

Concerning RQ2 (Which tools are being used to support the design of inclusive applications for multiple devices?), six studies presented solutions for the design of inclusive applications for multiple devices (see Table 8), representing $3.41 \%$ of the whole data extraction (see Fig. 2). According to the data, the types of technologies used to design inclusive applications for multiple devices were Platform (from 2007), the Framework (from 2011 and 2012) and the Application (from 2009). Thus, only three types of technologies were proposed. New strategic approaches for reuse and flexibility were not addressed, such as the Software Product Line. In comparison to the Software Engineering approaches used by the identified studies, the SPL may support higher reduction in software development costs, higher increase of software quality, faster time to market and higher reduction in maintenance efforts [10]. In this way, with these advantages, it is intriguing that this approach has never been used in the design of tools to support the development of such applications. Thus, this information could demonstrate some level of detachment between HCI and Software Engineering. In contrast, it may also demonstrate that the software engineering methodologies need to advance in order to take into account inclusiveness as a very important non-functional requirement. Through the analysis of the papers included in this review, it could also be noticed the interest of several studies to evolve Web technologies. Indeed, some of these studies have explored the Semantic Web and Ontologies technologies to automatize interface generation.

Furthermore, the results reported in this review also show that the underserved audience is still under addressed by inclusive design studies (see Table 12). By contrast, the number of studies that attends the elder audience is substantial (Fig. 5) - which reveals the concern of researchers with the older population. Considering the devices used in the studies, the large presence of mobile phones in these studies can be highlighted (see Table 5). It can also be noted a smaller amount of works focusing on Tablets (compared to mobile phones); however it is expected an increase in the number of studies which address this kind of device as well as smartphones because both devices are becoming more and more popular. Additionally, it can be perceived a trending convergence of devices in the studies. All the identified inclusive design works for multiple devices (Table 7) were published in the last seven years.

For the best of our knowledge, there is no previous systematic review that answers the research questions of this work. Nevertheless, some analyzed studies present secondary studies (surveys) that address HCI aspects for the design of multiple devices and different kinds of disabilities (e.g., [11] [12] [13]). 


\subsection{Threats To Validity}

This section discusses the threats to validity that might have affected the results of this systematic review. The review protocol was validated to ensure that the research was as correct, complete and objective as possible. However, possible limitations in two moments of the review process were identified: in the publication selection and in the data extraction.

The search for publications was performed in two major steps: (i) automatic search and (ii) manual search. In step (i) there is a limitation because the search string could not be used in SpringerLink library, which possibly leads to a reduction in the considered studies. In step (ii), it was identified a limitation concerning the papers included in the review. The manual search was performed only on a limited set of journals and conferences and it was expected that relevant studies published in other journals or conferences would be captured through the automatic search realized in the previous step. However, it cannot be guaranteed that all related papers published are included in this review. Moreover, it is possible that some kind of inaccuracy or misclassification have occurred in the data extraction performed in this systematic review, mainly because the data extraction was done individually by the researchers.

\section{Conclusions}

Web movement beyond desktop to different devices increased the challenges for accessibility, while, at the same time, this movement amplified the possibilities to ensure access to information for all. This paper presented a systematic review on the design for different users and multiple devices. Thus, a roadmap towards inclusive environments was drawn based on the extracted data in order to answer two research questions: "RQ1. Which interface design approaches are being used to address multiple devices and users with different conditions?" and "RQ2. Which tools are being used to support the design of inclusive applications for multiple devices?". A systematic review protocol was defined and the automatic and manual search returned a total of 4061 studies between 2002 and 2012. After applying the exclusion/inclusion criteria, it led to the inclusion of 176 studies in the review.

The results indicated that: i) the HCI community is presenting solutions for the software development lifecycle until the software deployment, but only few researches are considering software evolution and interaction design during use time; ii) there is a gap between the software engineering and the HCI communities regarding the subject, because some more recent software engineering approaches for development and maintenance are not in the analyzed work yet; in the same way that software engineering approaches need to consider inclusiveness as an important non-functional requirement; iii) a connection between the HCI and the Semantic Web and ontologies communities could be identified. Some included studies explored Semantic Web and ontologies technologies to automate user interface generation; iv) it is important for the HCI community to increase the number of studies addressing underserved people and also to interact with local research communities addressing this problem; v) there is a growing curve on the number of publications on the subject addressed by this work, in the last decade. 
As further work, we expect to: i) diminish the threats to validity, ii) analyze the studies according to each disability, iii) analyze each ID approach based on software development lifecycle, iv) evaluate each provided tool by developing inclusive environments, v) propose new ID approaches to cover software development, maintenance, and dynamic evolution, and finally, vi) extend the study to consider other research questions and more papers of relevant authors identified in this systematic review.

Acknowledgements. This work has been supported by the Brazilian Institutions: Conselho Nacional de Desenvolvimento Científico e Tecnológico (CNPq), processes: 150113/2013-7 and 560044/2010-0 (EcoWeb Project).

\section{References}

1. Medeiros, C.B.: Grand research challenges in computer science in Brazil. Computer 41, 59-65 (2008)

2. Calvary, G., Coutaz, J., Thevenin, D., Limbourg, Q., Bouillon, L., Vanderdonckt, J.: A Unifying Reference Framework for multi-target user interfaces. Interacting with Computers 15, 289-308 (2003)

3. Gajos, K.Z., Weld, D.S., Wobbrock, J.O.: Automatically generating personalized user interfaces with Supple. Artificial Intelligence 174, 910-950 (2010)

4. Falb, J., Popp, R., Rock, T., Jelinek, H., Arnautovic, E., Kaindl, H.: Fully-automatic generation of user interfaces for multiple devices from a high-level model based on communicative acts. In: 2007 40th Annual Hawaii International Conference on System Sciences (HICSS 2007), p. 26 (2007)

5. Kitchenham, B.: Procedures for performing systematic reviews, TR/SE-0401, Department of Computer Science, Keele University, Keele, Staffs, UK (2004)

6. Beecham, S., et al.: Motivation in Software Engineering: A systematic literature review. Inform. Softw. Technol (2007), doi:10.1016/j.infsof.2007.09.004

7. Almeida, L.D.A., Baranauskas, M.C.C.: Accessibility in Rich Internet Applications: People and Research. In: Proceedings of IHC 2012, 11th Brazilian Symposium on Human Factors in Computing Systems, vol. 1, pp. 3-12 (2012)

8. Buchdid, S.B., Baranauskas, M.C.C.: IHC em contexto: o que as palavras relevam sobre ela. In: IHC 2012, Proceedings of Brazilian Symposium on Human Factors in Computing Systems, Cuiabá, vol. 1, pp. 199-208 (2012)

9. Biolchini, J., Mian, P.G., Candida, A., Natali, C.: Systematic Review in Software Engineering. Engineering 679, 165-176 (2005)

10. Pohl, K.: Software Product Line Engineering. Springer (2005)

11. Loureiro, B., Rodrigues, R.: Multi-touch as a Natural User Interface for elders: A survey. $\operatorname{IEEE}(2011)$

12. Economou, D., Gavalas, D., Kenteris, M., Tsekouras, G.E.: Cultural applications for mobile devices: Issues and requirements for authoring tools and development platforms. ACM SIGMOBILE Mobile Computing and Communications Review 12, 18 (2008)

13. Seffah, A., Forbrig, P., Javahery, H.: Multi-devices "Multiple" user interfaces: development models and research opportunities. Journal of Systems and Software 73, 287-300 (2004) 